\title{
DETERMINATION OF METHANE SOURCEX GLOBALLY BY SCIAMACHY
}

\author{
J. G. Park ${ }^{\mathrm{a}}$, S. Y. Park \\ ${ }^{\text {a }}$ Dept. of Informatics, Tokyo University of Information Sciences, 4-1 Onaridai, Wakabaku, Chiba-city, Japan - \\ amon@rsch.tuis.ac.jp \\ ${ }^{\text {b }}$ Dept. of Internatioal Biobusiness Studies, Tokyo University of Agriculture, 1-1-1 Sakuragakak, Sedagayaku, Tokyo, Japan - \\ s3paku@nodai.ac.jp
}

Commission, WG VIII/3

KEY WORDS: Methane, Methane Sources, Emission concentration, SCIAMACHY, Broadleaf evergreen forest

\begin{abstract}
:
Since the beginning of the industrial revolution, the atmospheric concentration of carbon dioxide $\left(\mathrm{CO}_{2}\right)$ has increased by nearly $30 \%$, and the Methane $\left(\mathrm{CH}_{4}\right)$ concentration has more than doubled. $\mathrm{CH}_{4}$ is the second most important greenhouse gas, after $\mathrm{CO}_{2}$. Emissions, extrapolated from measurements of actual gas flux from wetlands, vary from place to place, even within the same wetland. This high variability makes large-scale estimates difficult and means that average emissions levels include a large degree of estimated uncertainty. The SCIAMACHY instrument on the European Space Agency satellite ENVISAT measured greenhouse gases in the troposphere and stratosphere. In this study, the $\mathrm{CH}_{4}$ source area is extracted by estimating the concentrations of methane emissions from time-series satellite data. Contamination of the data by cloud is interpolated both spatially and temporally. It is assumed that methane emission is negligible over ocean and that the concentration in the ocean area is due to advection from land. Background $\mathrm{CH}_{4}$ concentration on land was defined as the ocean $\mathrm{CH}_{4}$ concentration at the same latitude. $\mathrm{Land} \mathrm{CH}_{4}$ emission concentrations show that areas of concentrated high $\mathrm{CH}_{4}$ emission are not in paddy fields only but also in broadleaf evergreen areas in South America and Central Africa.
\end{abstract}

\section{INTRODUCTION}

Looking at the long-term trend, the global average temperature increased by $0.74 \pm 0.18^{\circ} \mathrm{C}$ over the 100 -year period ending in 2005 (IPCC, 2007). If global warming continues in the same way, changes in temperature and precipitation patterns are expected over the long term of 50 to 100 years, while changes in the intensity and frequency of extreme weather conditions are expected over the short term. Extreme weather conditions, in particular, often lead to massive damage and analysis of them is an important topic in the context of analyzing global warming (Trenberth and Shea, 2005).

Much research has found that the main cause of global warming is increased greenhouse gases in the atmosphere due to the use of fossil fuels by humans and is not a natural phenomenon (IPCC, 2007; Houweling et al., 2000). Greenhouse gases are materials in the atmosphere that absorb and re-emit some of the infrared light radiated from the surface of the earth. Carbon dioxide $\left(\mathrm{CO}_{2}\right)$, methane $\left(\mathrm{CH}_{4}\right)$, dinitrogen monoxide $\left(\mathrm{N}_{2} \mathrm{O}\right)$ and chlorofluorocarbon gases are all greenhouse gases.

The global warming potential (GWP) is a numeric indicator that represents how much a particular greenhouse gas contributes to global warming. GWP is defined as the integral of the amount of radiative energy emitted into the atmosphere per unit mass of greenhouse gas over some fixed period (such as 20 years, 100 years, or 500 years), with the values taken relative to $\mathrm{CO}_{2}$. Across 100 years, $\mathrm{CH}_{4}$ has a global warming effect of 25 (that is, 25-fold the effect of CO2), $\mathrm{N}_{2} \mathrm{O}$ has an effect of 310 , and chlorofluorocarbons have an effect of several thousand to tens of thousands (IPCC, 2007; Forester et al., 2007). Comparing the concentration levels present before the industrial revolution with the mean concentrations in 2012, $\mathrm{CO}_{2}$ concentrations have increased from $278 \mathrm{ppm}$ to $393.1 \pm 0.1 \mathrm{ppm}$ (a 41\% increase), $\mathrm{CH}_{4}$ has increased from $700 \mathrm{ppb}$ to $1819 \pm 1 \mathrm{ppb}(160 \%)$, and $\mathrm{N}_{2} \mathrm{O}$ has increased from $270 \mathrm{ppb}$ to $325 \pm 0.1 \mathrm{ppb}(20 \%)$. The increases in the greenhouse gases since the industrial revolution as characterized by the GWP are $63 \%$ for $\mathrm{CO}_{2}, 18 \%$ for $\mathrm{CH}_{4}$, $6 \%$ for $\mathrm{N}_{2} \mathrm{O}$, and $13 \%$ for other (IPCC, 2007). This is found by multiplying the proportions of gases present with the GWP for each gas.

Observation of $\mathrm{CO}_{2}$ as a greenhouse gas began in 1957 at the South Pole and in 1958 at Mauna Loa, Hawaii. An increase in $\mathrm{CO}_{2}$ was clearly seen from the observations at Mauna Loa, and this was one of the catalysts for the theory of international global warming. Measurements of greenhouse gases have been conducted by the World Data Center for Greenhouse Gases (WDCGG). The WDCGG was established under the Global Atmosphere Watch (GAW) process of the World Meteorological Organization (WMO), and the WDCGG collects, manages, and provides data on gases (CO, $\mathrm{NOX}, \mathrm{SO}_{2}$, etc.) related to greenhouse gases $\left(\mathrm{CO}_{2}, \mathrm{CH}_{4}, \mathrm{CFCs}, \mathrm{N}_{2} \mathrm{O}\right)$ measured in the atmosphere and ocean.

Satellite measurement data are available from the Scanning Imaging Absorption Spectrometer for Atmospheric Chartography (SCIAMACHY) sensor mounted on the Environmental Satellite (ENVISAT), which was launched on 1 March 2002 by the European Space Agency (ESA) (Burrows et al., 1995) and from the Greenhouse Gases Observing Satellite (GOSAT), which was launched on 23 January 2009 through cooperation between the Japan Aerospace Exploration Agency (JAXA), the National Institute for Environmental Studies (NIES) of Japan, and the Ministry of the Environment (MOE) of Japan. Although the greenhouse gas data measured by the WDCGG cover only a narrow range of geographical locations relative to the globe, satellite collection allows measurement over two-dimensional areas and is often used in research covering wide areas (Berggamaschi et al., 2007; Bracher et al., 2005; Buchwitz et al., 2006; Frankenberg et al., 2005).

As global warming intensifies, $\mathrm{CH}_{4}$ that has accumulated in permafrost and $\mathrm{CH}_{4}$ that is trapped in ice is released into the 
atmosphere, and this drives further warming. From 1974 to 2000 , the area of permafrost lakes increased by $14.7 \%$ and emissions increased by 58\% (Walter et al., 2006). Furthermore, it was recently found that $\mathrm{CH}_{4}$ is also emitted from tropical rainforest and grassland (Keppler et al., 2006; Wang et al., 2008).

Sources of $\mathrm{CH}_{4}$ are broadly divided into biological sources and non-biological sources. Non-biological sources of $\mathrm{CH}_{4}$ emissions include mining and burning of fossil fuels, burning of biomass, and garbage disposal. Biological sources include swamps, wet rice paddies, livestock, landfill, termites, and forests. In the complex processes of biological ecosystems, $\mathrm{CO}_{2}$ is produced when organic matter is decomposed by anaerobic bacteria (via fermentation and putrescence), and $\mathrm{CH}_{4}$ is produced by an abundance of $\mathrm{CO}_{2}$ and methane bacteria (Conrad, 1996). Biological sources account for over $70 \%$ of total $\mathrm{CH}_{4}$ emissions (IPCC, 2007).

Emitters of $\mathrm{CH}_{4}$ include natural and artificial sources. Among natural sources, the largest sources of emissions are bogs and swamps, with emissions also occurring from termites and vegetation (Lelieveld et al., 1998; IPCC, 2007). Among artificial sources, the main sources are wet rice paddies, livestock, waste disposal processes, and mining and use of fossil fuels (Houweling et al., 2000; Ruddiman, 2003). Although there are also sinks for $\mathrm{CH}_{4}$, including absorption by soil (5\%) (IPCC, 2007 and Inagaki et al., 2004), decomposition by chemical reaction in the atmosphere accounts for over $87 \%$ of $\mathrm{CH}_{4}$ elimination. Decomposition by chemical reaction occurs via reaction with hydroxide radicals (OH radicals) by means of chemical reactions involving sunlight, oxygen, ozone, water vapor, etc. (Brasseur et al., 1999).

The amount of $\mathrm{CH}_{4}$ that is emitted from sources such as swamps and wet rice paddies has been clarified by many field observations (Walter and Heimann, 2001a,b; Christemsen et al., 2003; Wickland et al., 2006). However, the amount of $\mathrm{CH}_{4}$ emitted varies according to differences in the observation targets and environment. Furthermore, it is difficult to apply data from a narrow observation region to a more global region. Research has therefore also been conducted by using satellite remote sensing technology, which offers wide geographic ranges and temporal periodicity. Frankenberg (2005) shows that $\mathrm{CH}_{4}$ concentrations are high in tropical rainforest zones. However, since the background $\mathrm{CH}_{4}$ concentration was not excluded, accurately determining the source of $\mathrm{CH}_{4}$ was difficult.

There are many details of emissions that are insufficiently understood to accurately identify emission sources with the emission quantities in the $\mathrm{CH}_{4}$ balance. For example, the amount of $\mathrm{CH}_{4}$ emitted differs with the model and the field survey method. Estimates of the amount of anthropogenic methane emitted vary greatly between research methods, with a low value of $264 \mathrm{Tg}\left(\mathrm{CH}_{4}\right)$ yr-1 given by by Scheele et al. (2002), a value of $358 \mathrm{Tg}\left(\mathrm{CH}_{4}\right) \mathrm{yr}-1$ by Wuebbles and Hayhoe (2002), and a high value of $428 \mathrm{Tg}\left(\mathrm{CH}_{4}\right) \mathrm{yr}-1$ by Chen and Prinn (2006) using the global inverse model. Furthermore, although the concentration of methane in the atmosphere remained virtually constant from 1999 to 2006, it began increasing again in 2007 (Rigby et al., 2008). It has been noted (WMO Greenhouse Gas Report, 2014) that no variations in the amount of emissions from the Arctic Circle have been observed, despite $\mathrm{CH}_{4}$ emissions from the tropical zones and lower latitudes in the northern hemisphere, and the exact reason for the increase is currently unknown.

In this research, we therefore estimated the surface concentration of methane emissions and extracted the $\mathrm{CH}_{4}$ sources by using time-series data from SCIAMACHY covering the period from 2003 to 2011. We treat the surface background $\mathrm{CH}_{4}$ concentration, which has been problematic in other research, as the $\mathrm{CH}_{4}$ concentration over ocean at the same latitude, and then calculate the surface concentration of $\mathrm{CH}_{4}$ emissions under this assumption. Furthermore, we compare the topographical features of $\mathrm{CH}_{4}$ sources with vegetation maps to investigate the sources of $\mathrm{CH}_{4}$ emissions..

\section{DATA}

\subsection{SCIAMACHY}

SCIAMACHY was mounted on ENVISAT and operated from February 2002 to April 2012. The main aim of SCIAMACHY was to measure the various greenhouse gases (including $\mathrm{O}_{3}$, $\mathrm{BrO}, \mathrm{SO}_{2}, \mathrm{HCHO}, \mathrm{OCIO}, \mathrm{H}_{2} \mathrm{O}, \mathrm{CH}_{4}, \mathrm{CO}_{2}, \mathrm{~N}_{2} \mathrm{O}, \mathrm{CO}$, and $\mathrm{NO}_{2}$ ) and atmospheric pollutants in the troposphere and stratosphere. SCIAMACHY had 8 spectroscopic channels, ranging from ultraviolet to near infrared range (240 to $2380 \mathrm{~nm}$ ). The ENVISAT satellite was a polar orbiting satellite that orbited Earth 14 times per day at an altitude of $800 \mathrm{~km}$ in space. In the data, the measurement width is $960 \mathrm{~km}$ and the surface resolution is $30 \mathrm{~km}$ north-south and 60 to $120 \mathrm{~km}$ east-west. The vertical column density (VCD) data for $\mathrm{CH}_{4}$ are retrievable by using the iterative maximum a posteriori (IMAP)-DOAS method of Frankenberg et al. (2005). The dataset used in this research was downloaded from the SCIAMACHY website (http://www.sciamachy.org/products/index.php?species=CH4).

\subsection{GLCMNO}

The Global Land Cover by National Mapping Organizations (GLCNMO) was created by the Geospatial Information Authority of Japan and by Chiba University through cooperation with the National Mapping Organization (NMO), in which 181 countries around the world participate. The land cover layer of the GLCNMO is available as a cluster dataset divided into 20 items according to the land cover classification system (LCCS) developed by the Food and Agriculture Organization of the United Nations (FAO). The landcover legend includes evergreen broad-leaf forest, deciduous broadleaf forest, evergreen needle-leaf forest, deciduous needle-leaf forest, mixed forest, grassland, fields, wet rice paddies, mangroves, swamps, bare ground (sand), and bare ground (pebbles and stone) (Tateishi et al., 2014).

This research uses the first revision of the 1-km resolution data. The first revision is the result of categorizing by using the MODIS data from 2003. GNCNMO performs sampling at a resolution of $30 \times 60 \mathrm{~km}$ to perform comparison with the $\mathrm{CH}_{4}$ source distribution. During sampling, the proportion of land cover for each pixel is calculated.

\section{METHOD}

\subsection{Cloud-free Images}

Optical sensor data obtained from satellites are often unclear near the ground surface due to the effects of clouds. We therefore created cloud-free images by determining whether or not an observation point was affected by cloud and using only those data that were not affected by cloud. We used the observation data obtained during a prior pass to make this determination when generating the maps. We used the threshold data (selection_criteria.txt) from the SCIAMACHY product site (ftp://ftp.sron.nl/pub/pub/DataProducts/SCIAMACHY_CH4/) as the threshold values when creating the cloud-free images. 


\subsection{Spatial Interpolation and Time-series Interpolation}

When a large proportion of data is missing due to the effects of cloud, analysis becomes difficult. We used spatial and timeseries interpolation to impute missing data. For this, we note that the concentration of $\mathrm{CH}_{4}$ in the atmosphere varies depending on the amounts of $\mathrm{CH}_{4}$ emitted and destroyed. Furthermore, the concentration also varies, depending on advection from the surroundings. In order to accurately estimate the missing data, therefore, it is necessary to reproduce the atmospheric trace components and variations. We use a threedimensional chemistry-transport model for this. However, many of the data items needed in order to accurately employ a threedimensional chemistry-transport model are not easy to obtain, particularly the auxiliary data and initial values required by the model, so it is difficult to process globally.

In this research, we therefore assumed that the concentration of $\mathrm{CH}_{4}$ varied gradually with the surrounding concentration environment, and specifically that there are no sudden variations over short periods of time across narrow ranges. In this work, we did not consider the effects of air currents that vary by altitude. Under the above assumptions, we used spatial interpolation and time-series interpolation to simply estimate the missing data.

For spatial interpolation of the missing data, we used a weighted spatial filter with a size of $7 \times 5$ pixels. First, we divided the 34 pixels surrounding the target pixel into 8 regions, and if pixels without cloud existed in at least one pair of opposite directions $\left(0^{\circ}\right.$ and $180^{\circ}, 45^{\circ}$ and $225^{\circ}, 90^{\circ}$ and $270^{\circ}$, $135^{\circ}$ and $315^{\circ}$ ), the value for the target pixel was interpolated by applying the $7 \times 5$ weighted filter. For this, the weighting was applied inversely linearly proportional to the distance from the target pixel.

A necessary condition for time-series interpolation of $\mathrm{CH}_{4}$ concentration in the atmosphere was that the $\mathrm{CH}_{4}$ concentration did not change sharply over a short period of time (here, less than 30 days). For example, if a target pixel was missing, the value was found by linear interpolation using the data before (15 days before) and after (15 days after) the target pixel. Where two sets (30 days) or more of consecutive data were missing, interpolation was not performed. Figure 1 shows an example of time-series interpolation by using preceding and following time period data for the case of a missing target pixel. When the fifth data point is missing, linear interpolation is performed using the fourth (1728) and sixth (1732) data points. However, for data points 21 and 22, interpolation is not performed because consecutive data points are missing.

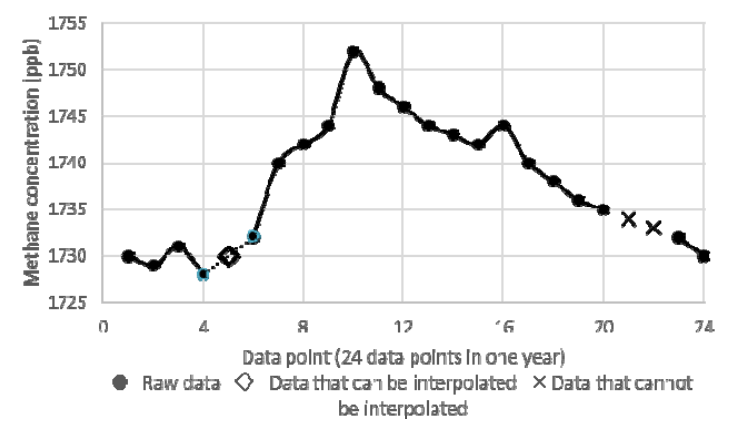

Figure 1. Time-series interpolation

\subsection{Concentration of $\mathrm{CH}_{4}$ Emission}

The $\mathrm{CH}_{4}$ concentrations in ocean regions at lower latitudes of the northern hemisphere are higher than in continental regions of the southern hemisphere, despite the fact that virtually no $\mathrm{CH} 4$ is emitted over ocean regions. In the lower latitudes of the northern hemisphere, there is a large distribution of wet rice paddies, which are a $\mathrm{CH}_{4}$ source, and the $\mathrm{CH}_{4}$ that is emitted over land flows by advection to neighboring ocean regions. Figure 2 shows a simplified overview diagram of advection of the $\mathrm{CH}_{4}$ emitted over land into the atmosphere. The $\mathrm{CH}_{4}$ concentrations that are observed by satellite are the $\mathrm{CH}_{4}$ concentrations that exist in the atmosphere directly under the satellite, rather than the $\mathrm{CH}_{4}$ concentrations emitted from the land surface directly under the satellite. To determine the $\mathrm{CH}_{4}$ concentration emitted from the land surface (defined here as the $\mathrm{CH}_{4}$ emission concentration), the $\mathrm{CH}_{4}$ concentration that already exists in the atmosphere (i.e., background $\mathrm{CH}_{4}$ concentration) needs to be known. However, the background $\mathrm{CH}_{4}$ concentration cannot be found easily because it varies with location and time.

Emission of $\mathrm{CH}_{4}$ in ocean regions is extremely low in comparison with that in continental regions, and the $\mathrm{CH}_{4}$ observed in continental regions is mainly due to advection from land regions. Although air currents vary complexly depending on autorotation, solar heating, terrain, and altitude, in this research we simplified the treatment of air currents. To simplify the air currents, we treat the $\mathrm{CH}_{4}$ concentration in ocean regions at a given latitude as the background $\mathrm{CH}_{4}$ concentration over continental regions at the same latitude.

The $\mathrm{CH}_{4}$ emission concentration at a location is then found by determining the difference between the $\mathrm{CH}_{4}$ concentration over continental regions and the background $\mathrm{CH}_{4}$ concentration (ocean-region methane concentration) at the same latitude (Eq. $1)$.

$\mathrm{CH}_{4}$ emission concentration = continental $\mathrm{CH}_{4}$ concentration ocean $\mathrm{CH}_{4}$ concentration (average at same latitude)

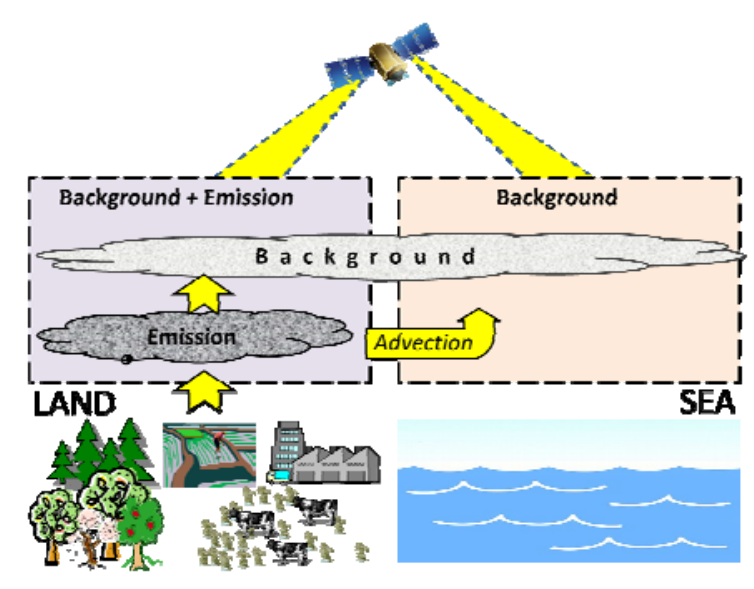

Figure 2 Overview diagram of advection of $\mathrm{CH}_{4}$ emitted over land into the atmosphere

\section{RESULT}

\subsection{3-stage Interpolation for cloud-free image}

In this research, we perform 3-stage processing (spatial interpolation followed by time-series interpolation followed by 
further spatial interpolation) in order to interpolate for the missing data. Figure 3(a) shows 15-day maximum-value composite images, created using the cloud determination threshold. Figures 3(c)-(d) show the results of the 3-stage interpolation process, using cloud-free composite images from 16 to 30 July 2003. 4(a) for the northern part of Japan. Figure 3(b) shows the results of applying the $7 \times 5$ spatial filter to Figure 3(a). Interpolation was performed with a weighting corresponding to the distance from the center pixel where the opposing components were present in a $7 \times 5$ spatial filter centered on the missing pixel. Figure 3(c) is the result of performing linear interpolation by using the previous and following period data for pixels that could not be interpolated by performing spatial interpolation. Many of the missing pixels in the Sea of Japan and Pacific Ocean were filled in by this method of interpolation. Finally, Figure 3(d) shows the results of spatially interpolating the results of the time-series interpolation once more with the $7 \times 5$ spatial filter. In the highlatitude regions in both the northern and southern hemispheres, data are missing for winter because of the high solar zenith angles.

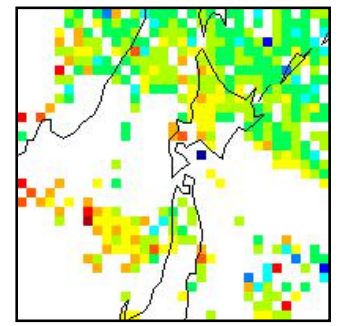

(a)15-day composite image

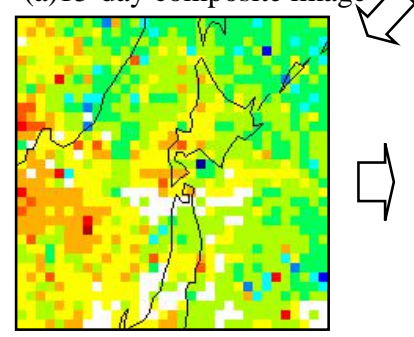

(c) Time-series Interpolation

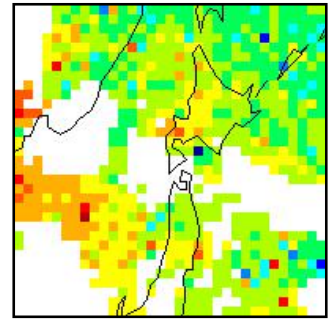

(b) Spatial Interpolation

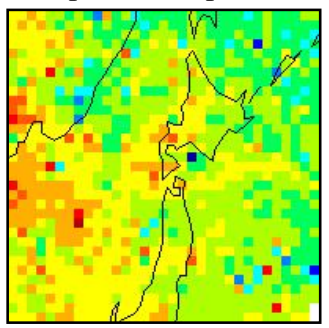

(d) Spatial Interpolation
Figure 3. 3-stage interpolation of data missing due to the effects of cloud

\subsection{Time-series Variations in Methane Concentration}

The concentration of $\mathrm{CH}_{4}$ in the atmosphere varies with region and time. Figure 4 shows the changes in $\mathrm{CH}_{4}$ concentration between January, April, July, and October 2005. In the diagrams, higher (resp., lower) concentration of $\mathrm{CH}_{4}$ is indicated by redder (resp., bluer) color. In regions of high elevation, such as the Tibetan Plateau and the Andes, the concentration of $\mathrm{CH}_{4}$ is low. When the elevation is high, a lower concentration of $\mathrm{CH}_{4}$ concentration is observed because the distance from the upper edge of the atmosphere to the surface is smaller.

In the image for July, even in desert regions, where $\mathrm{CH}_{4}$ is not emitted, the $\mathrm{CH}_{4}$ concentration was $1730 \mathrm{ppb}$ in the Sahara Desert in Africa and 1670 ppb in the Great Sandy Desert in Australia, with a difference of approximately $60 \mathrm{ppb}$ in $\mathrm{CH}_{4}$ concentration. There is a wide distribution of wet rice paddies in Southeast Asia, in the same latitude range as the Sahara Desert, and the $\mathrm{CH}_{4}$ emitted from the wet rice paddies is thought to be transported via advection to the desert. Since there are few $\mathrm{CH}_{4}$ sources in the same latitude range as the Great Sandy Desert and a large area of ocean, advection from other locations is small. Differences in $\mathrm{CH}_{4}$ concentration in the atmosphere between the two desert regions can be attributed to differences in background concentration.

In the image for October, there is clearly advection of $\mathrm{CH}_{4}$, which is thought to have been emitted in western Africa and central Africa in July and later appeared over the Atlantic Ocean and Pacific Ocean. The advection is from the point of emission towards the west, and is thought to be due to the effect of westerly winds from the north east near the equator. Most regions in the northern hemisphere exhibit concentrations of 1700 to $1760 \mathrm{ppb}$, while the southern hemisphere exhibits concentrations 1660 to $1740 \mathrm{ppb}$, which is lower than in the northern hemisphere. This is because the background concentration that exists in the atmosphere is lower in the southern hemisphere because there are fewer $\mathrm{CH}_{4}$ emission sources than in the northern hemisphere. Regions where the $\mathrm{CH}_{4}$ concentration is high include the tropical rainforests of southern America and central Africa in January (1780 to 1850 ppb) and Southeast Asia from May to October (1850 to 1920 ppb). The regions of high $\mathrm{CH}_{4}$ concentration are thought to arise from differences in land use and cover. In many of the pioneering research studies, it has been reported that $\mathrm{CH} 4$ is emitted by wet rice paddies (Inubushi et al. 1989; Inubusuh et al. 1994; Kumagai and Konno 1998; Holzapfel and Seiler 1986) and there have also been reports noting that $\mathrm{CH}_{4}$ is emitted by other vegetation (Keppler et al., 2006; Wang et al., 2008).

It can be judged whether the $\mathrm{CH}_{4}$ concentration is high or low by using atmospheric $\mathrm{CH}_{4}$ concentrations, which include the background $\mathrm{CH}_{4}$ concentration. However, whether the $\mathrm{CH} 4$ emission concentration is high or low cannot be seen from data that include background concentration. We therefore need to remove the background concentration to allow comparison of the $\mathrm{CH}_{4}$ emission concentrations over continental regions.

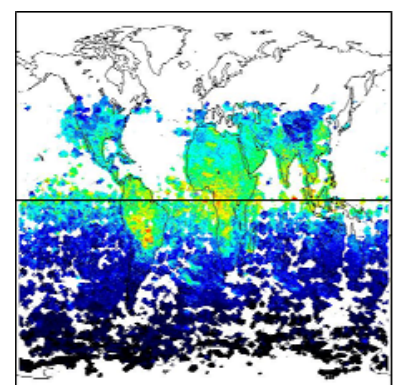

(a) January

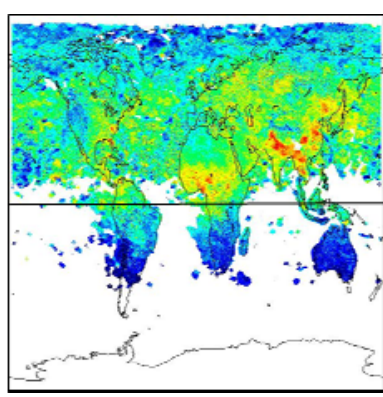

(c) July

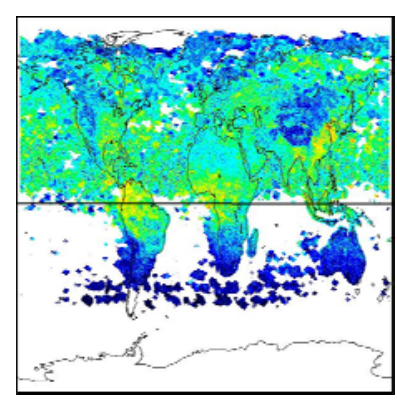

(b) April

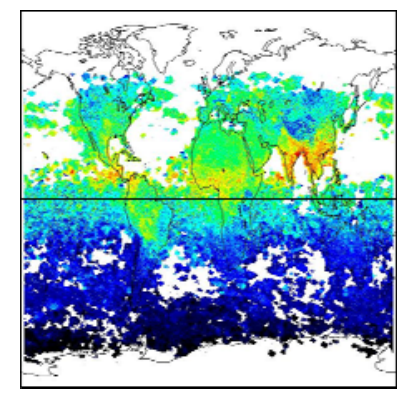

(d) October
Figure 4. Time-series changes in methane concentration 
4.3 Interannual Variations in Mean $\mathrm{CH}_{4}$ Concentration by Latitude Zone Over Continental Regions

Figure 5 shows the mean $\mathrm{CH}_{4}$ concentration by latitude zone $\left(0.3^{\circ}\right.$ spacing) using data for only continental regions over 9 years (216 data points), from 2003 to 2011. The white regions at high latitudes in both the southern and northern hemispheres are time periods of data loss due to the effects of clouds or high solar zenith angles.

Seasonal variations can be seen in the mean $\mathrm{CH}_{4}$ concentration, with low values in spring, increasing values from summer through autumn, and low values in winter. In the distribution by latitude zone, the concentration takes a maximum near $15^{\circ} \mathrm{N}$ latitude, with the concentration decreasing closer to the polar region. There are many wet rice paddies (which are a $\mathrm{CH}_{4}$ source) located in the range of $10^{\circ} \mathrm{N}$ to $23^{\circ} \mathrm{N}$, and the $\mathrm{CH}_{4}$ concentration exhibits a maximum of $1850 \mathrm{ppb}$ from August to October. Furthermore, the southern hemisphere exhibited a level of $1660 \mathrm{ppb}$, which is $70 \mathrm{ppb}$ lower than the $1730 \mathrm{ppb}$ of the northern hemisphere. This difference is due to having fewer $\mathrm{CH}_{4}$ sources. It is clear that although the interannual variations in $\mathrm{CH}_{4}$ were low from 2003 to 2006, from 2007 the concentrations increased annually, centered on the lower latitudes of the northern hemisphere, and the range of areas of higher concentration also spread.

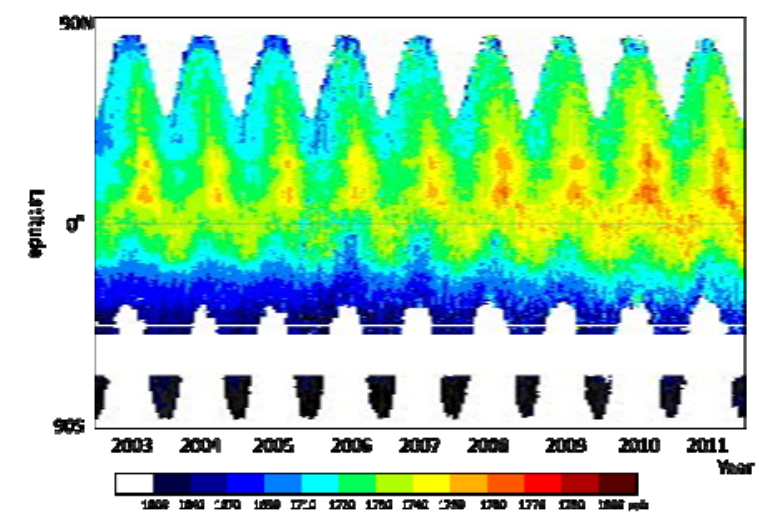

Figure 5. Interannual variation in mean $\mathrm{CH}_{4}$ concentration by latitude zone over continental regions

\subsection{CH4 Emission Concentration}

Using the levels of atmospheric $\mathrm{CH}_{4}$ concentration as measured by a satellite-based instrument to judge whether the amounts of $\mathrm{CH}_{4}$ emitted from ground regions are large or small is problematic. For example, the $\mathrm{CH}_{4}$ concentration of $1720 \mathrm{ppb}$ in the Sahara Desert in July 2005 (Figure 4) is higher than the concentration of $1670 \mathrm{ppb}$ over the forest region of Brazil. Despite this, virtually no $\mathrm{CH}_{4}$ is emitted from desert regions with little rain. In contrast, $\mathrm{CH}_{4}$ is emitted from vegetation and from the soil in the forest regions of tropical rainforests, and certainly more $\mathrm{CH}_{4}$ is emitted from these than from desert regions. Although the concentration of $\mathrm{CH}_{4}$ in the atmosphere is affected by the $\mathrm{CH}_{4}$ emitted from the surface, it is also strongly influenced by the background $\mathrm{CH}_{4}$ concentration, which is already present in the atmosphere. In order to investigate the amount of $\mathrm{CH}_{4}$ emitted from the surface, it is essential to know the level of background concentration. We therefore assumed that the mean $\mathrm{CH} 4$ concentration over ocean regions is the background concentration for continental regions at the same latitude (Figure 2). Figure 6 shows the $\mathrm{CH}_{4}$ emission concentrations as obtained by subtracting the background $\mathrm{CH}_{4}$ concentrations at the same latitudes from the $\mathrm{CH}_{4}$ concentrations in Figure 4.

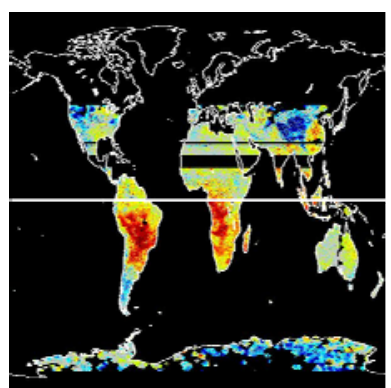

(a) January

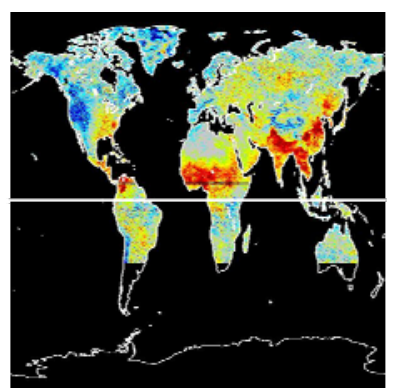

(c) July

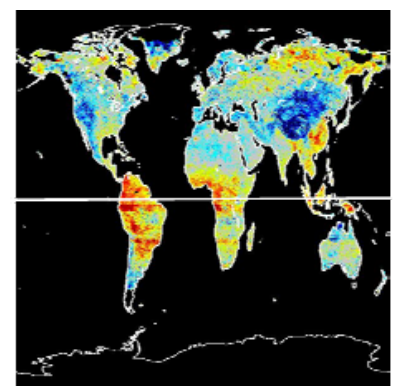

(b) April

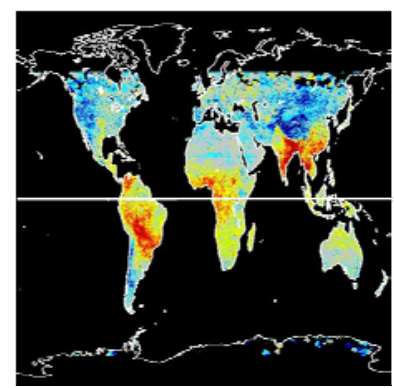

(d) October

Figure 6. Time-series $\mathrm{CH}_{4}$ emission concentration over continental regions

It is clear that a maximum of $100 \mathrm{ppb}$ of $\mathrm{CH}_{4}$ is emitted from the wet rice paddy region of Southeast Asia and $60 \mathrm{ppb}$ or more is emitted from West Africa and central Africa in July, and a maximum of $80 \mathrm{ppb}$ is emitted from South America from October to April. Although the Sahara Desert exhibits emission concentrations close to virtually $0 \mathrm{ppb}$, in April the methane emission concentrations are under-evaluated, at $-10 \mathrm{ppb}$. This is because the $\mathrm{CH}_{4}$ concentration on the Pacific Ocean side at the same latitude is $10 \mathrm{ppb}$ higher than in the desert region. This may be due to the effect of $\mathrm{OH}$ radical reactions (which are a methane sink), or the removal of cloud from the data for desert regions may not be sufficient; this needs to be investigated in detail in the future. In regions of high elevation, the emission concentrations are under-estimated because the atmospheric $\mathrm{CH}_{4}$ concentrations are low.

\subsection{Relation between $\mathrm{CH}_{4}$ Sources and Land Cover}

To investigate the land cover characteristics of $\mathrm{CH}_{4}$ sources, we performed a comparison with GLCNMO. Figure 7(a) shows the average annual emission concentration of $\mathrm{CH}_{4}$ for 2009. Higher $\mathrm{CH}_{4}$ emissions are indicated by redder color. Figure 7(b) shows the cover proportion of wet rice paddies from GLCNMO and Figure 7(c) shows the cover proportion of evergreen broad-leaf forest.

The emission concentrations of the main $\mathrm{CH}_{4}$ sources in China are $61 \mathrm{ppb}$ in the Dongting Lake in Hunan Province, 65 ppb in the Sichuan Basin, and $61 \mathrm{ppb}$ around the $\mathrm{Xi}$ River in Guangdong Province. The ratios of the land cover components around the Dongting Lake are $79 \%$ wet rice paddies and $19 \%$ fields. The Sichuan Basin is $25 \%$ wet rice paddies and $62 \%$ fields. The area around the Xi River in Guangdong Province is $31 \%$ wet rice paddies, $20 \%$ open trees, and $15 \%$ fields. The 
land cover characteristics of the $\mathrm{CH}_{4}$ sources in China are clearly wet rice paddies in proximity to lakes and rivers.

The emission concentrations of $\mathrm{CH}_{4}$ sources in Southeast Asia are 60 ppb in Lào Cai in Vietnam, 63 ppb in Nakhon Sawan in northern Thailand, and 63 ppb around the Yamuna River and Padma River in Bangladesh. The ratios of the land cover components in Lào Cai are $50 \%$ open trees, $22 \%$ wet rice paddies, and $11 \%$ evergreen broad-leaf forest. The Lào Cai region is famous for the Sa Pa terraced rice fields. Nakhon Sawan is $25 \%$ wet rice paddies, $25 \%$ fields, and $24 \%$ open trees. Nakhon Sawan includes the confluence of the Ping River, Wang River, Yom River, and Nan River. The area around the two rivers in Bangladesh is 53\% wet rice paddies, 30\% fields, and $12 \%$ open trees. In the wet rice paddies in Bangladesh, two growing seasons are employed, with Aman rice cultivation in the wet season and Boro rice cultivation in the dry season. From the land cover characteristics of the $\mathrm{CH}_{4}$ sources in Southeast Asia, there are clearly many wet rice paddies.

The emission concentrations of $\mathrm{CH}_{4}$ sources in South America are $61 \mathrm{ppb}$ around Magangué in Colombia and $75 \mathrm{ppb}$ around Santa Ana in Bolivia. The ratios of the land cover components around the Magangue are 48\% evergreen broad-leaf forest and $40 \%$ fields. In the area around Santa Ana into which the Mamoré River flows from the Andes, $38 \%$ is fields, $31 \%$ is open trees, and $23 \%$ is evergreen broad-leaf forest. Although there is also a scattering of swamps, the cover proportion of swamps is only $1 \%$. This shows that the land cover of $\mathrm{CH}_{4}$ sources in South America consists of a lot of fields and evergreen broad-leaf forest.

The emission concentrations of $\mathrm{CH}_{4}$ sources in western and central Africa are 46 ppb in Onitsha in Nigeria and 35 ppb in the coastal region of Cameroon, respectively. The ratios of the land cover components around Onitsha are 57\% evergreen broad-leaf forest and $29 \%$ shrub.

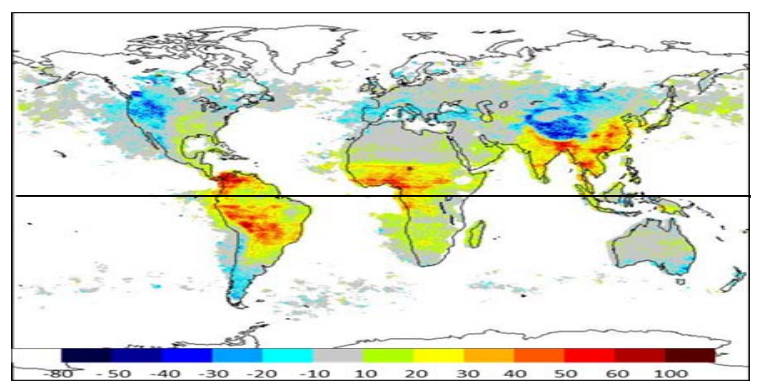

(a) Annual $\mathrm{CH}_{4}$ emission concentration for 2009

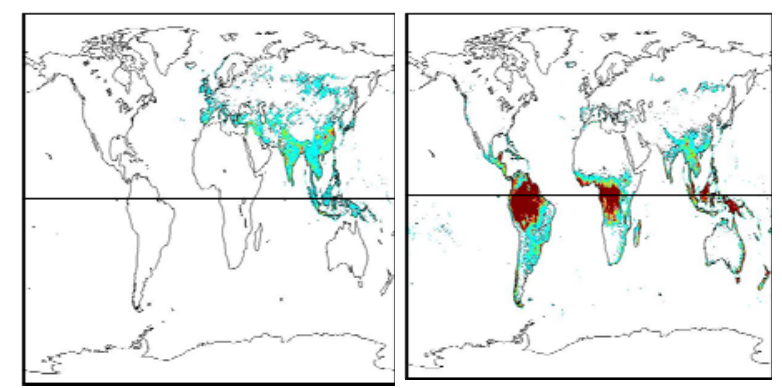

$\begin{array}{ll}\text { b) Coverage of rice paddies } & \text { (c) Coverage of evergreen }\end{array}$ broad-leaf forest

Figure 7. Mean annual $\mathrm{CH}_{4}$ emission concentration for 2009 and land cover coverage of rice paddies and evergreen broadleaf forest
The coastal region of Cameroon consists of $80 \%$ evergreen broad-leaf forest and $8 \%$ fields. This shows that the land cover of $\mathrm{CH}_{4}$ sources in Africa consists of a lot of evergreen broadleaf forest.The high-latitude regions in the northern hemisphere, which contain a lot of swamp, are missing from the analysis because sufficient data could not be obtained due to the solar zenith angle and the effect of cloud.

\section{CONCLUSIONS}

When investigating $\mathrm{CH}_{4}$ source distribution by using data measured via satellites, it is necessary to know the existing background concentration. In this research, we assumed that since $\mathrm{CH}_{4}$ is not emitted in ocean regions, any $\mathrm{CH}_{4}$ that does exist in the ocean regions is due to the effect of advection from continental regions. Furthermore, we simplify the complex atmospheric cycle model by treating the $\mathrm{CH}_{4}$ over the ocean to be advection from continental regions at the same latitude, as shown in Figure 2, and define the $\mathrm{CH}_{4}$ concentration over ocean regions as the background concentration at the same latitude. As a result the surface $\mathrm{CH}_{4}$ emissions concentrations are found from the difference between the surface $\mathrm{CH}_{4}$ concentration and the $\mathrm{CH} 4$ concentration in ocean regions at the same latitude.

In the IPCC (2007) presentation, the largest anthropogenic source of $\mathrm{CH}_{4}$ emissions was ruminant livestock (23-44\%) followed by wet rice paddies (12-26\%). From the results for the annual $\mathrm{CH}_{4}$ emissions concentrations (Figure 7), the wet rice paddy regions at the lower latitudes in the northern hemisphere, which are well-known as an existing source, were confirmed to be the largest anthropogenic source of $\mathrm{CH}_{4}$.

However, we newly found that tropical evergreen broad-leaf forests in South America and central and western Africa are $\mathrm{CH}_{4}$ sources, which was not previously widely known. Since these regions have a small proportion of fields and similar, it is thought that the $\mathrm{CH}_{4}$ emissions sources are natural sources, rather than artificial sources. At the IPCC meeting (2007), it was presented that swamp and termites are natural sources of $\mathrm{CH}_{4}$ emission.

Although swamps can also be considered as a natural $\mathrm{CH}_{4}$ source, the land cover proportion of swamp in the GLCNMO dataset is extremely small. Termites are also a $\mathrm{CH}_{4}$ emission source in tropical rainforest regions. Termites are widely distributed throughout tropical, subtropical, and temperate zones. Termites mainly consume the fiber (cellulose) of vegetation and emit $\mathrm{CH}_{4}$ through the process of fermentation of cellulose by microorganisms in their digestive organs. However, since there is little research on accurate distributions and quantities of termites, calculating the level of contribution by termites to $\mathrm{CH}_{4}$ emissions is difficult.

The land cover of natural $\mathrm{CH}_{4}$ sources was found to be primarily evergreen broad-leaf forest. Although some research has indicated that $\mathrm{CH}_{4}$ is emitted from vegetation, later research found that it is emitted primarily under special environmental conditions, such as strong ultraviolet light or high temperatures. From Figure 6, although seasonal variation occurs in the amount of $\mathrm{CH}_{4}$ emitted, this seasonal variation is not $\mathrm{CH}_{4}$ produced from the action of photosynthesis. Since the timeseries normalized difference vegetation index of evergreen broad-leaf forest has little annual variation, the photosynthesis activity is also thought to have little annual variation. Furthermore, not all of the evergreen broad-leaf forests are $\mathrm{CH}_{4}$ sources, as shown in Figure 7 (c). If $\mathrm{CH}_{4}$ is emitted from evergreen broad-leaf forests, then the $\mathrm{CH}_{4}$ source would be expected to extend even further into Brazil.

Seasonal variation in $\mathrm{CH}_{4}$ emission concentration in central and western Africa and South America is strongly tied to the wet 
season. According to the Koppen climate classification, these three regions have climates of tropical rainforest, savannah, and tropical monsoon. The tropical rainforest climate has a lot of rain year-round, and the savannah climate and tropical monsoon climate are divided into a wet season (in central Africa the wet season is from May to July) and a dry season (in Brazil the dry season is from May to September). When the wet season arrives, the ground surface temporarily changes into an anaerobic environment due to the abundance of rain, and $\mathrm{CH}_{4}$ is readily emitted as a result. $\mathrm{CH}_{4}$ that is produced underground is emitted above ground from the leaves of plants by evapotranspiration of the plant (Megonigal and Guenther, 2008). Furthermore, it is thought that $\mathrm{CH}_{4}$ that is produced near the ground surface diffuses directly into the atmosphere.

\section{FUTURE WORK}

In this research, we used satellite data to investigate the distribution of $\mathrm{CH}_{4}$ sources. As a result, we found that a lot of $\mathrm{CH}_{4}$ is emitted from evergreen broad-leaf forest regions in tropical rainforest climates, in addition to the known emissions from wet rice paddies. Although the IPCC (2007) report estimated that much more $\mathrm{CH}_{4}$ emissions come from anthropogenic sources than from natural sources, the results of this research showed that natural $\mathrm{CH}_{4}$ sources are more widely distributed than anthropogenic sources. However, changes in the amount of emissions from natural sources are expected to be small unless there are notable changes in the environment. The extraordinary increase in $\mathrm{CH}_{4}$ since the industrial revolution is clearly the result of anthropogenic sources.

As problems for the future, we need to investigate the timeseries changes in the $\mathrm{CH}_{4}$ sources that were found in this research and clarify the cause of increases in $\mathrm{CH}_{4}$ since 2007. The emission sources of $\mathrm{CH}_{4}$ can be investigated in more detail by investigating time-series changes in $\mathrm{CH}_{4}$ emissions, timeseries changes in vegetation, and time-series changes in temperature and precipitation.

\section{ACKNOWLEDGEMENTS}

This research was supported in part by the Environment Research and Technology Development Fund (1-1405) of Ministry of Environment, Japan; and by a MEXT Japan grantin-aid for scientific research (No. 26350403) and JSPS Grantin-Aid for Scientific Research (No. 25340014).

\section{REFERENCES}

Kazuyuki Inubushi, Kenzo Hori, Satoshi Matsumoto, Masanao Umebayashi, Hidenori Wada, 1989. Methane Emission from the Flooded Paddy Soil to the Atmosphere through Rice Plant, Journal of the science of soil and manure, Japan, 60(4), 318-324

Kazuyuki Inubushi, Yasuhiko Muramatsu, Masanao Umebayashi, 1994. Effect of Incorporation-timing of Rice Straw on Methane Emissions from Paddy Soil, Journal of the science of soil and manure, Japan, 65(1), 22-26

Katsumi Kumagai and Yoichi Konno, 1998. Methane Emission from Rice Paddy Fields after Upland Farming, Journal of the science of soil and manure, Japan, 69(4), 333-339

Yoshiyuki Inagaki, Shigehiro Ishizuka, Tadashi Sakata, Masamichi Takahashi, Hidehisa Fukata, 2004. The effect of thinning on carbon dioxide emission and methane uptake by forest soils in Hinoki cypress (Chamaecyparis obtusa) plantations, Applied Forest Science, Japan, 13(2), 91-96, The Society of Applied Forest Science

Bergamaschi, P., Frankenberg, C., Meirink, J. F., Krol, M., Fentener, F., Wagner, T., Platt, U., Kaplan, J. O., Korner, S., Heimann, M., Dlugokencky, E. J., and Goede, A., 2007: Satellite chartography of atmospheric methane from SCIAMACHY on board ENVISAT: 2. Evaluation based on inverse model simulations, J. Geophysical Res. 112,D02304, doi:10.1029/2006JD007268

Bracher,A., Lamsal,L. N., Weber, M., Bramstedt, K., Coldewey-Egbers, M., and Burrows, J. P., 2005: Global satellite validation of SCIAMACHY O3 columns with GOME WFDOAS, Atmos. Chem. Phys., 5, PP.2357-2368

Brasseur, G., Orlando, J., Tyndall, G. (Editors), 1999: Atmospheric Chemistry and Global Change. Topics in Environmental Chemistry. Oxford University Press, New York, 654 pp.

Buchwitz, M., de Beek, R., Noel, S., Burrows, J. P., Bovensmann, H.,Schneising, O., Khlystova, I., Bruns, M., Bremer, H., Bergamaschi, P., Korner, S., and Heimann, M. 2006: Atmospheric carbon gases retrieved from SCIAMACHY by WFM-DOAS: version $0.5 \mathrm{CO}$ and $\mathrm{CH} 4$ and impact of calibration improvements on $\mathrm{CO} 2$ retrieval, Atmos. Chem. Phys., 6, PP.2727-2751

Burrows, J. P., H“olzle, E., Goede, A. P. H., Visser, H., and Fricke, W., 1995: SCIAMACHY - Scanning Imaging Absorption Spectrometer for Atmospheric Chartography, Acta Astronautica, 35(7), 445-451

Chen, Y-H., and R.G. Prinn, 2006: Estimation of atmospheric methane emission between 1996-2001 using a 3-D global chemical transport model. J. Geophys. Res., 111, D10307, doi:10.1029/2005JD006058.

Christensen, T.R., A. Ekberg, L. Ström, and M. Mastepanov, 2003: Factors controlling large scale variations in methane emission from wetlands. J. Geophysical Res. Lett., 30, 1414, doi:10.1029/2002GL016848.

Conrad, R., 1996: Soil microorganisms as controllers of atmospheric trace gases (H2, CO, CH4, OCS, N2O, and NO). Microbiol. Rev., 60, 609-640

IPCC, 2007, Climate Change 2007: The Physical Science Basis. Contribution of Working Group I to the Fourth Assessment Report of the Intergovernmental Panel on Climate Change,S. Solomon, D. Qin, M. Manning, Z. Chen, M. Marquis, K.B. Averyt, M. Tignor and H.L. Miller (Eds) (Cambridge, UK: Cambridge University Press).

Forster, P., Ramaswamy, V., Artaxo, P., Berntsen, T., Betts, R., Fahey, D.W., Haywood, J., Lean, J., Lowe, D.C., Myhre, G., Nganga, J., Prinn, R., Raga, G., M., S., Van Dorland, R., 2007: Changes in Atmospheric Constituents and in Radiative Forcing. In: S. Solomon et al. (Editors), Climate Change 2007: The Physical Science Basis. Contribution of Working Group I to the Fourth Assessment Report of the Intergovernmental Panel on Climate Change. Cambridge University Press, Cambridge, U.K. 
Frankenberg, C., J. F. Meirink, M. van Weele, U. Platt, T. Wagner, 2005: Assessing methane emissions from global spaceborne observations. Science, 308, 5724, 1010?1014, DOI: 10.1126/science.1106644.

Frankenberg, C., Platt, U., and Wagner, T.: 2005b: Iterative maximum a posteriori (IMAP)-DOAS for retrieval of strongly absorbing trace gases: Model studies for $\mathrm{CH} 4$ and $\mathrm{CO} 2$ retrieval from near infrared spectra of SCIAMACHY onboard ENVISAT, Atmos. Chem. Phys., 5, 9-22.

Holzapfel-Pschorn. A and Seiler. W, 1986: Methane emission during a cultivation period from an Italian rice paddy, Journal of Geophysical research Atmospheres,11803-11814 DOI:10.1029/JD091iD11p11803

Houweling, S., F. Dentener, and J. Lelieveld, 2000: Simulation of preindustrial atmospheric methane to constrain the global source strength of natural wetlands. J. Geophys. Res., 105, 17243-17255.

Keppler, F.,Hamilton, J.T.G., Brass.M. and Rockmann, T., 2006: Methane emissions from terrestrial plants under aerobic conditions. Nature, 439, pp. 187-191.

Lelieveld, J., Crutzen, P.J. and Dentener, F.J., 1998: Changing concentration, lifetime and climate forcing of atmospheric methane. Tellus, 50B, pp. 128-150.

Megonigal, J., Patrick and Guenther Alex., 2008: Methane emissions from forest soils and vegetation. Tree Physiology 28, pp.491-498.

Rigby, M., Prinn, R. G., Fraser, P. J., Simmonds, P. G., Langenfelds, R. L., Huang, J., Cunnold, D. M., Steele, L. P., Krummel, P. B., Weiss, R. F., O’Doherty, S., Salameh, P. K.,Wang, H. J., Harth, C. M., M“uhle, J., and Porter, L. W. , 2008: Renewed growth of atmospheric methane, J. Geophysical Res. Lett., 35, L22805, doi:10.1029/2008GL036037.

Ruddiman, W.F., 2003: The anthropogenic greenhouse era began thousands of years ago. Climatic Change 61, 261-293.

Scheehle, E.A., W.N. Irving, and D. Kruger, 2002: Global anthropogenic methane emission. In: Non-CO2 Greenhouse Gases [Van Ham, J., A.P. Baede, R. Guicherit, and J.WilliamsJacobse (eds)]. Millpress, Rotterdam, pp. 257-262.

Tateishi, R., Hoan, N. T., Kobayashi, T., Alsaaideh, B., Tana, G., and Phong, D. X., 2014 : Production of Global Land Cover Data - GLCNMO2008 , Journal of Geography and Geology; Vol.6, No.3, PP.99-122

Trenberth, K.E., and D.J. Shea, 2005: Relationships between precipitation and surface temperature. J. Geophysical Res. Lett., 32, L14703, doi:10.1029/2005GL022760

Wang, Z.-P., Han, X.-G., Wang, G.G., Ssong, Y. and Gulledge, J., 2008: Aerobic methane emission from plants in the Inner Mongolia steppe. Environmental Science and Technology, 42, pp. 62-68

Walter, B.P., and M. Heimann, 2001a: Modeling modern methane emission from natural wetlands, 1 . Model description and results. J. Geophysical Res., 106, 34189-34206.
Walter, B.P., and M. Heimann, 2001b: Modeling modern methane emission from natural wetlands, 2. Interannual variations 1982-1993. J. Geophysical Res., 106, 34207-37219.

Walter, K. M., Zimov S. A.,Chanton, J. P., Verbyla, D., and Chapin, F. S., 2006: Methane bubbling from Siberian thaw lakes as a positive feedback to climate warming, nature 443, pp71-75 doi:10.1038/nature05040.

Wickland, K., R. Striegl, J. Neff, and T. Sachs, 2006: Effects of permafrost melting on $\mathrm{CO} 2$ and $\mathrm{CH} 4$ exchange of a poorly drained black spruce lowland. J. Geophysical Res., 111, G02011, doi:10.1029/2005JG000099.

Wuebbles, D.J., and K. Hayhoe, 2002: Atmospheric methane and global change. Earth Sci. Rev., 57, 177-210

Japan Meteorological Agency Translation, 2014: WMO Annual Greenhouse Gas Bulletin No. 10

http://www.sciamachy.org/products/index.php?species=CH4 (accessed 6 Oct. 2015) 